\title{
PERANCANGAN SISTEM INFORMASI REKAM MEDIS PADA KLINIK XYZ BERBASIS JAVA
}

\author{
Adam Wahyu Nugraha ${ }^{1}$, Maria Cleopatra ${ }^{2}$, Noor Komari Pratiwi ${ }^{3}$ \\ 1,2,3 Universitas Indraprasta PGRI \\ Jl. Raya Tengah No. 80, Kel. Gedong, Kec. Pasar Rebo, Jakarta Timur 13760, Jakarta \\ 1. adamwahyu.rpl2@gmail.com, ${ }^{2}$ mariacleopatra1313@gmail.com, ${ }^{3}$ noorkomaripratiwi01@gmail.com
}

\begin{abstract}
ABSTRAK
Perkembangan teknologi informasi pada saat ini tidak dapat terhindar dari penggunaan komputer. Klinik yang merupakan institusi pelayanan kesehatan membutuhkan sistem informasi rekam medis sehingga pengolahan data tidak dilakukan secara manual mencegah adanya kesalahan data dan efisiensi penyimpanan. Tujuan dilakukannya penelitian ini adalah untuk merancang dan menerapakan suatu sistem informasi rekam medis yang membantu dan mempermudah petugas Klinik XYZ dalam melakukan pencatatan rekam medis pasien. Sistem informasi rekam medis pada Klinik XYZ berbasis java mencakup pengolahan data rekam medis, data pasien, data obat, dan data dokter. Penelitian ini menggunakan metode penelitian kualitatif yaitu dengan metode studi lapangan untuk pengambilan data, yaitu melalui pengamatan langsung, wawancara dengan pihak terkait, serta melakukan dokumentasi untuk mendapatkan informasi yang dibutuhkan. Metode pengembangan sistem menggunakan metode waterfall yang bertujuan untuk menganalisis permasalahan yang terjadi di Klinik XYZ dan merancang sebuah sistem informasi rekam medis yang dapat diimplementasikan dalam bentuk aplikasi berbasis komputer. Hasil penelitian ini yaitu adanya suatu aplikasi sistem informasi yang dibuat dari bahasa pemrograman Java NetBeans dan sistem penyimpanan data menggunakan database MySQL. Dalam membangun sistem ini, digunakan alat bantu pembuatan sistem yaitu activity diagram, use case diagram, class diagram, dan sequence diagram. Dapat disimpulkan, sistem informasi yang dirancang ini dapat mempermudah dan membantu petugas klinik dalam melakukan proses rekam medis di Klinik XYZ.
\end{abstract}

Kata Kunci: Sistem Informasi, Rekam Medis, UML, Java, $M y S Q L$

\begin{abstract}
The development of information technology at this time cannot be avoided from the use of computers. Clinics, which are health care institutions, need a medical record information system so that data processing is not done manually to prevent data errors and storage efficiency. The purpose of this research is to design and implement a medical record information system that helps and facilitates XYZ Clinic staff in recording patient medical records. The medical record information system at the Java-based XYZ Clinic includes processing medical record data, patient data, drug data, and doctor data. This study uses qualitative research methods, namely the field study method for data collection, namely through direct observation, interviews with related parties, and conducting documentation to obtain the required information. The system development method uses the waterfall method which aims to analyze the problems that occur at XYZ Clinic and design a medical record information system that can be implemented in the form of computer-based applications. The result of this research is the existence of an information system application made from the Java Netbeans programming language and a data storage system using a MySQL database. In building this system, used tools for making the system, namely activity diagrams, use case diagrams, class diagrams, and sequence diagrams. It can be concluded, this designed information system can facilitate and assist clinic staff in carrying out the medical record process at XYZ Clinic.
\end{abstract}

Key Word: Application System, Medical Records, UML, Java, MySQL

\section{PENDAHULUAN}

Perkembangan teknologi informasi dan sistem informasi pada zaman modern seperti sekarang ini telah membuat hampir semua aspek kehidupan tidak dapat terhindar dari penggunaan komputer. Fungsi dari penggunaan komputer adalah sebagai alat untuk menciptakan sistem yang efektif dan efisisien terutama dalam hal penyajian informasi. Peran teknologi informasi yang bertugas sebagai pengolah data menjadi informasi yang bermanfaat sangat diperlukan untuk memperoleh informasi yang sesuai dengan pekerjaan yang lebih mudah sehingga data lebih akurat, efektif, dan efisien (Setiatin \& Agustin, 2019).

Klinik yang merupakan institusi pelayanan kesehatan membutuhkan sistem informasi yang baik serta memadai untuk menunjang 
dan memberikan pelayanan kepada para pasien serta pada lingkungan masyarakat setempat. Tata cara administrasi yang sederhana, mudah, dan cepat merupakan satu di antara peningkatan pelayanan. Proses pencarian data pasien yang cepat, baik pasien yang terdaftar maupun pasien baru belum terdaftar, akan berpengaruh pada pelayanan yang diinginkan oleh pasien, temasuk pengelolaan rekam medis data pasien.

Setiap dokter maupun dokter gigi dalam melaksanakan praktik kedokteran harus membuat rekam medis. Pelaksanaan rekam medis ini perlu dibuat dan harus dilengkapi setelah pasien mendapat pelayanan. Perancangan rekam medis dilakukan melalui pendokumentasian dan catatan hasil pemeriksaan pasien, pengobatan pasien, tindakan dokter dan pelayanan lainnya yang diberikan kepada pasien (Permenkes No. 269 Tahun 2008).

Klinik XYZ merupakan tempat praktik yang bergerak di bidang pelayanan kesehatan serta penyedia obat-obatan yang peduli dengan kesehatan masyarakat setempat. Setiap hari, Klinik XYZ melayani banyak transaksi rekam medis pasien. Hal tersebut bertentangan dengan sistem informasi yang digunakan dalam proses pelayanannya karena pelayanan klinik masih menggunakan informasi rekam medis secara manual. Hal ini menimbulkan beberapa kesulitan, seperti kesulitan dalam pencarian data, klasifikasi pasien, dan pembuatan laporan. Penggunaan rekam medis yang masih manual tersebut membuat banyak kesalahan dalam penyimpanan dan pengolahan data. Untuk itu, dalam pengelolaan rekam medis, klinik harus membuat sistem terkomputerisasi untuk mencegah adanya kesalahan data dan penyimpanan sehingga menjadi lebih efektif dan efisien dalam hal penyajian dan penyimpanan data yang dibutuhkan.

Berdasarkan permasalahan tersebut, diperlukan penggunaan sistem informasi yang menggunakan alat bantu komputer untuk pengolahan data rekam medis. Dengan memperhatikan sistem manual yang ada pada saat ini, objek yang diteliti, dan laporan yang akan ditampilkan, diharapkan sistem informasi yang dibangun dapat mengatasi permasalahan yang ada pada saat ini.
Sistem informasi adalah himpunan data yang saling melengkapi dan terintegrasi dengan menghasilkan keluaran yang baik untuk memecahkan masalah serta dalam pengambilan keputusan yang bersifat administratif dengan strategi dari kegiatan suatu organisasi untuk dapat mempersiapkan kepada pihak tertentu dengan pelaporan yang dibutuhkan (Sutabri, 2012).

Rekam medis adalah arsip yang berisikan dokumen dan catatan tentang identitas, pemeriksaan pasien, pengobatan pasien, tindakan dokter dan pelayanan lainnya yang diberikan kepada pasien (Permenkes No. 269 Tahun 2008).

Tujuan dirancangnya sistem informasi rekam medis pada Klinik XYZ berbasis java adalah untuk membantu petugas Klinik XYZ agar menjadi lebih efektif dan efisien dalam mengelola rekam medis pasien, data tersimpan menjadi lebih aman, dan kemudahan dalam pembuatan laporan.

Penggunaan sistem informasi rekam medis akan membantu proses pengumpulan, pengolahan, dan penyajian data dengan lebih baik. Informasi yang dihasilkan dapat dijadikan dasar bagi pihak manajemen untuk mengambil keputusan terkait perbaikan dan peningkatan kualitas pelayanan. Sistem informasi rekam medis diperlukan sebagai sarana penyedia informasi dan layanan bagi penggunanya, baik untuk paramedis, dokter, pasien, maupun karyawan, karena informasi yang didapat lebih akurat sehingga proses rekam medis dapat dilakukan lebih efektif dan efisien (Putranto, dkk., 2017).

\section{METODE PENELITIAN}

Dalam menyelesaikan penelitian ini, peneliti menggunakan pendekatan deskriptif. Artinya, data yang dihimpun bukan berupa angka, melainkan data yang berasal dari catatan lapangan, naskah wawancara, dokumen pribadi, memo peneliti atau catatan dan dokumen resmi yang mendukung. Tujuan menggunakan pendekatan kualitatif adalah agar peneliti dapat menggambarkan realita empiris di balik fenomena yang terjadi terkait dengan peran Klinik XYZ dalam melayani pasien sehingga data rekam medis pasien disimpan secara terkomputerisasi. 
Pada penelitian ini, peneliti mencocokkan antara peristiwa yang terjadi dengan teori menggunakan metode deskriptif yang berlaku. Metode penelitian kualitatif dapat diartikan sebagai model penelitian yang menghasilkan kreasi dan tidak didapat dengan cara menggunakan aturan-aturan statistik atau prosedur-prosedur lain dari kuantifikasi (Sayidah, 2018).

Pertimbangan peneliti menggunakan penelitian kualitatif ini, yaitu penelitian kualitatif teknik pengumpulan data yang digunakan observasi dan wawancara. Observasi, peneliti mengamati bagaimana petugas menerima dan mencatat pasien baru masuk dalam buku register penerimaan pasien pada lembaran masuk RM sehingga dapat menghasilkan laporan yang diperlukan. Wawancara, peneliti melakukan wawancara kepada petugas dan pasien bagaimana proses pelayanan yang diberikan pihak klinik terhadap pasien. (Siyoto \& Sodik, 2015).

Langkah-langkah pengembangan sistem yang digunakan penulis adalah dengan menggunakan metode waterfall. Model waterfall melakukan pendekatan secara berurutan dan sistematis. Disebut dengan waterfall dikarenakan setiap langkah yang dilewati pada tahap sebelumnya harus menunggu terlebih dahulu dan berjalan berurutan (Fathoroni et al., 2020).

Rancangan kegiatan dimulai pada bulan April 2021 dengan cara mengadakan survei langsung ke tempat penelitian diadakan, yaitu dengan observasi dan dokumentasi.

Penelitian dilakukan di Bimbingan dan Klinik XYZ yang terletak di Jl. Nusa Indah Raya Blok 40 No. 17H RT/RW 12/3 Kelurahan Malaka Jaya Kecamatan Duren Sawit, Jakarta Timur dimulai selama 4 bulan pada bulan April tahun 2021 sampai dengan bulan Juli tahun 2021.

Netbeans adalah sebuah aplikasi Integrated Development Environment (IDE) untuk membuat aplikasi dengan berbagai bahasa pemrograman desktop seperti java dan banyak digunakan sampai saat ini sebagai editor untuk berbagai macam bahasa pemrograman (Nofriadi, 2018).
MySQL adalah sebuah sistem manajemen database SQL (bahasa Inggris: database management system) yang jenisnya merupakan database relasional dan banyak digunakan untuk pembuatan aplikasi web maupun desktop yang multi-user dan multithread (Solichin, 2016).

XAMPP adalah paket perangkat lunak sumber terbuka yang bertindak sebagai tuan rumah yang berisi distribusi Apache untuk server Apache, MariaDB, PHP, dan Perl untuk mendukung jenis data dalam pembuatan aplikasi yang sedang dikembangkan (Saputra \& Aprilian, 2020).

\section{HASIL DAN PEMBAHASAN}

Berdasarkan hasil penelitian masalah sebelumnya, peneliti memberikan analisis permasalahan dari sistem pengelolaan data di antaranya.

1. Membutuhkan banyak waktu dalam melakukan rekam medis karena proses berjalan manual menjadi kurang efektif dan efisien.

2. Pengelolaan data pasien yang rumit baik yang sudah terdaftar atau data pasien baru yang belum terdaftar karena pengarsipan masih dalam bentuk kertas.

3. Terjadi penumpukan berkas data rekam medis karena terbatasnya tempat penyimpanan.

Berdasarkan masalah yang terdapat pada Klinik XYZ, penulis memberikan beberapa alternatif penyelesaian masalah tersebut.

1. Membuat sistem informasi rekam medis berbasis java, agar pekerjaan berjalan lebih efektif dan efisien.

2. Menggunakan media penyimpanan database MySQL agar data dapat disimpan di server untuk mencegah terjadinya kehilangan atau kerusakan data.

3. Menggunakan iReport Library pada Netbeans untuk membuat laporan yang dibutuhkan dan otomatis tersambung dengan aplikasi, agar pembuatan laporan lebih efektif dan efisien. Penggunaaan iReport juga mengurangi kemungkinan kesalahan pada pembuatan laporan.

\section{Use Case Diagram Sistem yang Diusulkan}

Berikut adalah gambaran sistem yang diusulkan untuk Klinik XYZ: 


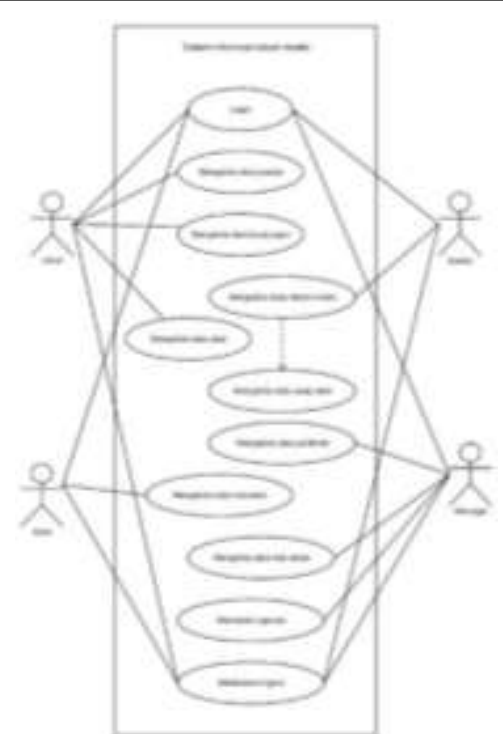

Gambar 1. Use Case Diagram Sistem

Pada use case diagram sistem yang diusulkan terdapat.

1. 1 (satu) sistem mencakup seluruh kegiatan.

2. 4 (empat) actor yang melaksanakan kegiatan, diantaranya dokter, admin, kasir, dan kepala unit.

3. 11 (sebelas) use case yang dilakukan dan dijalankan oleh actor tersebut diantaranya: melakukan $\log i n$, mengakses fitur data pasien, data dokter, data poliklinik, data obat, data rekam medis, data rekam obat atau transaksi obat, data detail obat, data karyawan (admin, kasir, dan kepala unit), data laporan, dan melakukan logout.

\section{Class Diagram Sistem yang Diusulkan}

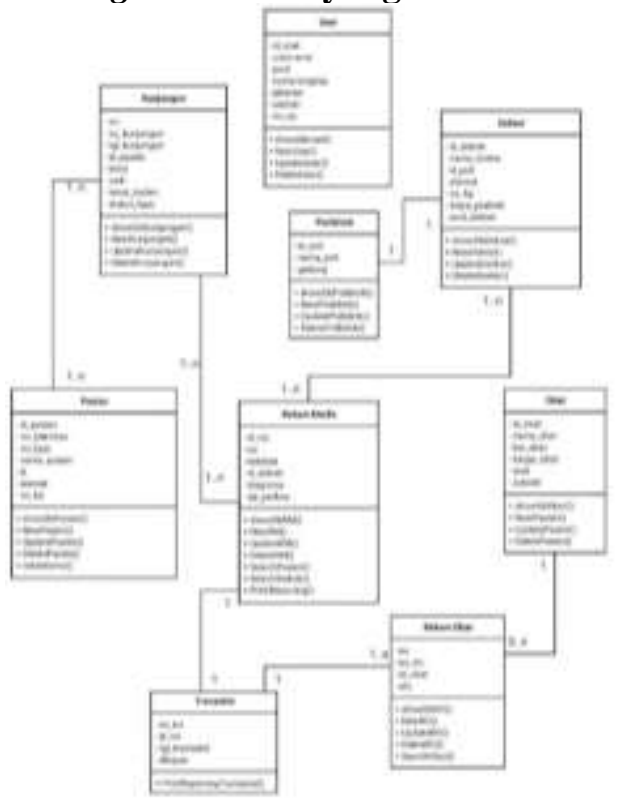

Pada class diagram sistem yang diusulkan, terdapat.

1. 1 (satu) sistem yang mencakup seluruh kegiatan.

2. 9 (sembilan) class.

3. 52 (lima puluh dua) atribut.

4. 39 (tiga puluh sembilan) operasi atau method.

\section{Tampilan Menu Home}

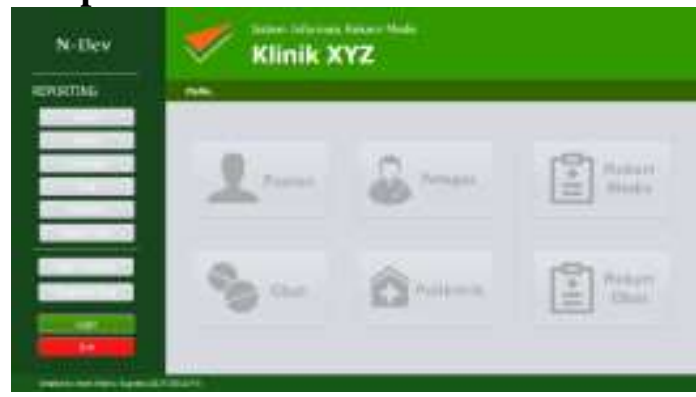

Gambar 3. Tampilan Menu Home

Pada tampilan home terdapat.

1. Menu utama, yaitu pasien, petugas, obat, poliklinik, rekam medis, dan rekam obat. Di dalam menu pasien terdapat form dan data pasien serta kunjungan, di dalam menu petugas terdapat form dan data dokter, admin, dan kasir, di dalam menu obat terdapat form dan data obat, di dalam menu poliklinik terdapat form dan data poliklinik, di dalam menu rekam medis terdapat form dan data rekam medis pasien, di dalam menu rekam obat terdapat form dan data resep dokter.

2. Menu samping untuk data laporan pasien, dokter, kunjungan, obat, poliklinik, rekam medis, data transaksi, dan penjualan obat.

3. Tombol Log In aplikasi.

4. Tombol Exit.

\section{Tampilan Form Log In}

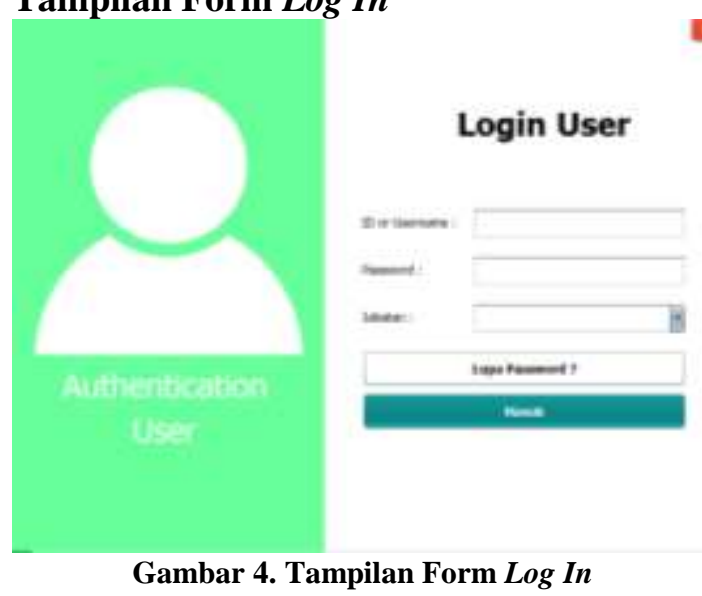

Gambar 2. Class Diagram Sistem 
Pada tampilan form log in terdapat.

1. 3 (tiga) JTextField untuk memasukkan ID atau username pengguna, password pengguna, dan jabatan pengguna.

2. 3 (tiga) JButton untuk lupa password, masuk aplikasi, dan exit form.

\section{Tampilan Form Kunjungan Pasien}

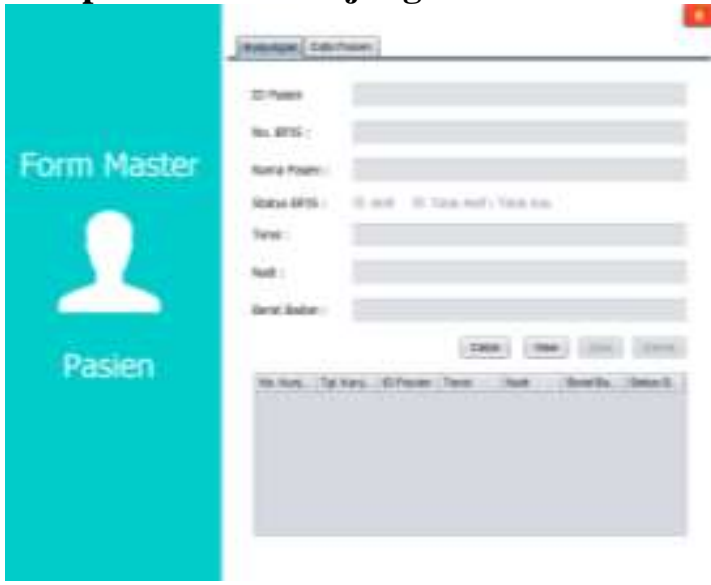

Gambar 5. Tampilan Form Kunjungan Pasien

Pada tampilan form kunjungan terdapat.

1. 6 (enam) JTextField untuk memasukkan ID pasien, tensi darah, denyut nadi, dan berat badan serta menampilkan nomor BPJS dan nama pasien.

2. 2 (dua) JRadioButton untuk memilih salah satu status keaktifan anggota BPJS.

3. 5 (lima) JButton untuk menambahkan data kunjungan pasien baru, memperbarui data kunjungan, menghapus data kunjungan, mencetak nomor kunjungan atau antrian, dan exit form.

4. 1 (satu) JTable untuk menampilkan seluruh data kunjungan pasien dalam satu hari.

\section{Tampilan Form Pendaftaran Pasien}

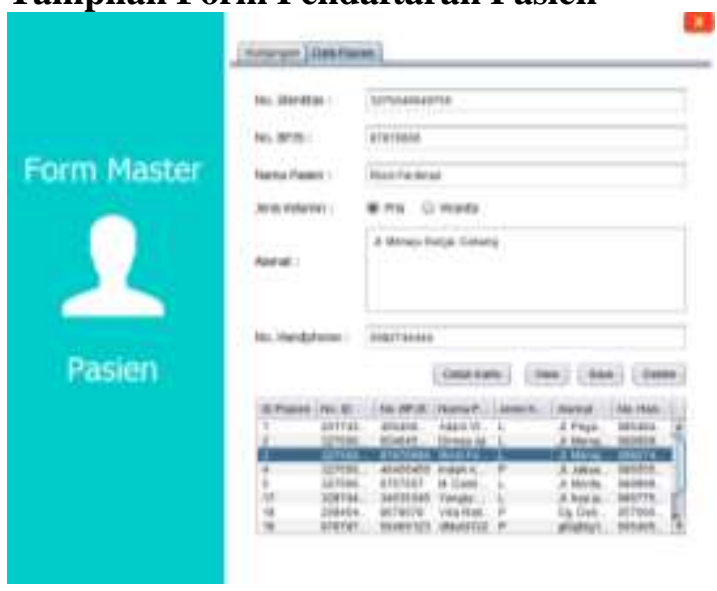

Gambar 6. Tampilan Form Pendaftaran Pasien
Pada tampilan form pendaftaran pasien terdapat.

1. 4 (empat) JTextField untuk memasukkan nomor identitas, nomor BPJS, nama pasien, dan nomor handphone.

2. 2 (dua) JRadioButton untuk memilih salah satu jenis kelamin pasien.

3. 1 (satu) JTextArea untuk memasukkan detail alamat pasien.

4. 5 (lima) JButton untuk menambahkan data baru, memperbarui data, menghapus data, mencetak kartu pasien, dan exit form.

5. 1 (satu) JTable untuk menampilkan seluruh data pasien yang telah terdaftar.

\section{Tampilan Form Data Obat}

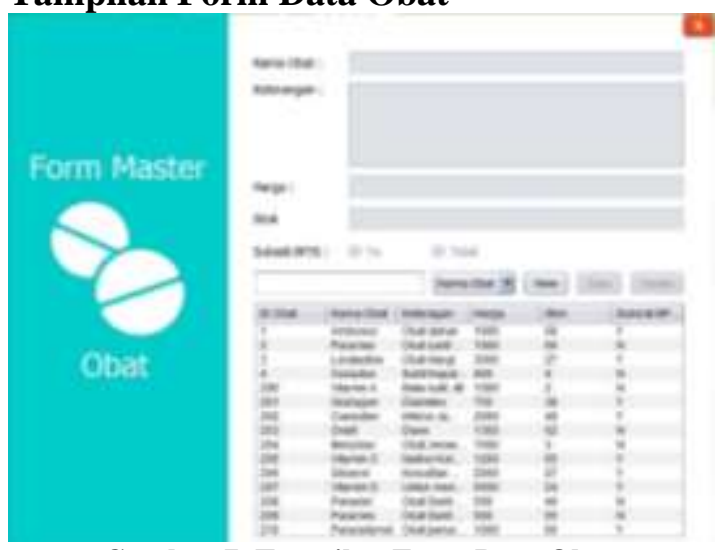

Gambar 7. Tampilan Form Data Obat

Pada tampilan form obat terdapat.

1. 4 (empat) JTextField untuk memasukkan nama obat, harga obat, stok obat, dan pencarian obat.

2. 1 (satu) JTextArea untuk memasukkan keterangan obat.

3. 2 (dua) JRadioButton untuk memilih salah satu jenis obat subsidi BPJS atau tidak.

4. 4 (empat) JButton untuk menambahkan data baru, memperbarui data, menghapus data, dan exit form.

5. 1 (satu) JComboBox untuk menyaring pencarian data obat berdasarkan nama obat, keterangan, harga, stok, dan subsidi.

6. 1 (satu) JTable untuk menampilkan seluruh data obat. 
Tampilan Form Rekam Medis Form Resinin Malk

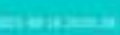

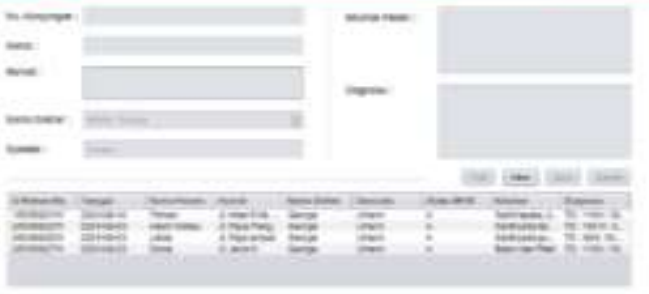

Gambar 8. Tampilan Form Rekam Medis

Pada tampilan form rekam medis terdapat.

1. 3 (tiga) JTextField untuk memasukkan nomor kunjungan kemudian menampilkan nama pasien dan spesialis dokter.

2. 3 (tiga) JTextArea untuk menampilkan alamat detail pasien dan untuk memasukkan keluhan pasien dan diagnosis pasien.

3. 1 (satu) JComboBox untuk menampilkan nama dokter.

4. 5 (lima) JButton untuk menambahkan data baru, memperbarui data, menghapus data, mencetak kartu rekam medis, dan exit form.

5. 1 (satu) JTable untuk menampilkan seluruh data rekam medis pasien.

\section{Tampilan Laporan Data Pasien}

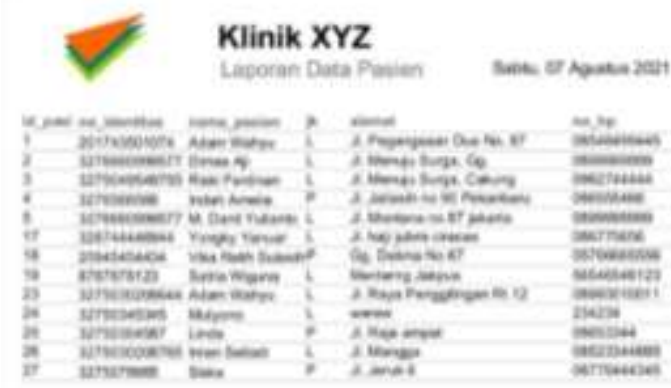

Gambar 9. Tampilan Laporan Data Pasien

Pada tampilan laporan data pasien terdapat gambar logo, nama klinik, judul laporan, tanggal laporan, dan data pasien yang telah mendaftar.
Tampilan Laporan Data Kunjungan

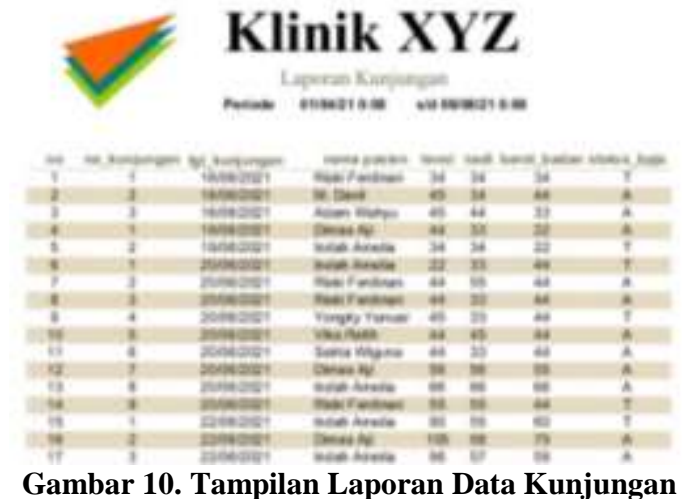

Pada tampilan laporan data kunjungan pasien terdapat gambar logo, nama klinik, judul laporan, tanggal laporan per periode, dan data pasien yang telah berkunjung.

\section{Tampilan Laporan Data Obat}

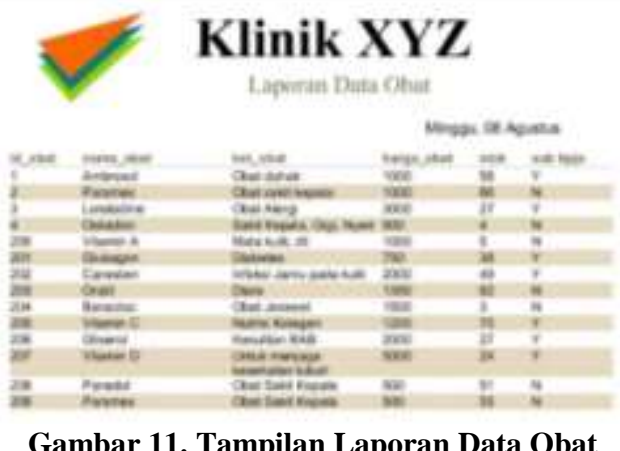

Pada tampilan laporan data obat terdapat gambar logo, nama klinik, judul laporan, tanggal laporan, dan data obat.

\section{Tampilan Laporan Data Rekam Medis}

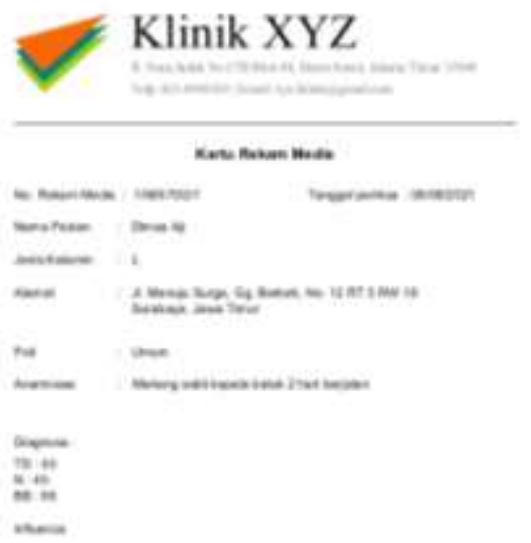


Pada tampilan laporan data rekam medis terdapat gambar logo, nama klinik, alamat klink, dan data rekam medis pasien.

\section{SIMPULAN DAN SARAN}

Berdasarkan hasil penelitian yang telah dilakukan pada Klinik XYZ, didapat beberapa simpulan sebagai berikut.

Sistem yang dirancang dapat memfasilitasi proses penyimpanan data rekam medis pasien yang terdiri dari identitas pasien, jenis pemeriksaan, pengobatan/pemberian resep, tindakan dan pelayanan lain kepada pasien pada sarana pelayanan kesehatan sehingga record dari pasien bisa tersimpan dengan baik.

Pada proses pengolahan data, sistem yang dibangun dapat membantu dalam proses pengolahan data. Sistem yang dirancang dapat menghasilkan laporan yang diperlukan oleh Kepala Klinik XYZ, meliputi laporan data pasien, kunjungan, rekam medis, obat, dan laporan lainnya.

Setelah penulis melakukan dan menganalisis sistem yang ada pada Klinik XYZ, penulis mengajukan beberapa saran. Adapun saran yang diusulkan adalah sebagai berikut:

Pengembangan sistem informasi lebih diperluas ke seluruh bagian kerja, tidak hanya terbatas pada pengolahan data pasien, rekam medis, dan pengolahan data pemeriksaan, tetapi untuk semua aktifitas yang terdapat pada Klinik XYZ.

Perlunya pengenalan dan pelatihan kepada petugas yang akan menggunakan sistem informasi ini sehingga dapat dipergunakan dengan baik. Sistem informasi rekam medis pada Klinik XYZ berbasis java dapat dikembangkan kembali dalam hal desain atau penambahan database sesuai kebutuhan sehingga dalam proses pengolahan data dan pembuatan laporan dapat dilakukan dengan lebih cepat dan mudah.

Hasil penelitian ini selaras dengan hasil penelitian yang menyimpulkan bahwa sistem informasi rekam medis mempermudah dalam melakukan perekapan, pengolahan, penyajian informasi, serta penyampaian informasi medis pasien.
DAFTAR PUSTAKA

Fathoroni, A., Fathonah, R. N. S., Andarsyah, R., \& Riza, N. (2020). Buku Tutorial Sistem Pendukung Keputusan Penilaian Kinerja Dosen Menggunakan Metode 360 Degree Feedback. Kreatif Industri Nusantara.

Kemenkes. (2008). Permenkes No 269 Tentang Rekam Medis. Kementerian Kesehatan Republik Indonesia.

Nofriadi. (2018). Java Fundamental dengan Netbeans 8.0.2. Deepublish.

Putranto, Y. Y., Putra, T. W. A., \& Hakim, F. N. (2017). Rancang Bangun Sistem Informasi Rekam Medis Klinik Berbasis Web (Studi Kasus: Klinik Utama Meditama Semarang). Jurnal Informatika UPGRIS, 3(2), 105-115. https://doi.org/10.26877/jiu.v3i2.1825

Saputra, M. H. K., \& Aprilian, L. V. (2020). Belajar Cepat Metode SAW. Kreatif Industri Nusantara.

Sayidah, N. (2018). Metodologi Penelitian Disertai Dengan Contoh Penerapannya Dalam Penelitian. Zifatama Jawara.

Setiatin, S., \& Agustin, S. R. (2019). Perancangan Sistem Informasi Pelayanan Rekam Medis di Puskesmas Arcamanik Kota Bandung. Jurnal Manajemen Informasi Kesehatan Indonesia, 7(1), 23-33.

Siyoto, S., \& Sodik, M. A. (2015). Dasar Metodologi Penelitian. Literasi Media Publishing.

Solichin, A. (2016). Pemrograman Web dengan PHP dan MySQL. Budi Lihur.

Sutabri, T. (2012). Konsep Sistem Informasi. Andi Offset. 